\title{
Failure investigation of a protective epoxy coating by means of crosscheck between infrared spectroscopy and thermal analysis
}

\author{
Luca Cozzarini a,b*, Lucia Marsich a,b, Alessio Ferluga ${ }^{b}$, Chiara Schmid a
}

(a) Department of Engineering and Architecture, University of Trieste, Trieste, Italy

(b) MaterialScan Srl., Trieste, Italy

* corresponding author: Luca Cozzarini - Icozzarini@units.it

\section{Highlights}

- an epoxy coating applied on the inner walls of a heat exchanger failed

- IR spectroscopy, thermal analysis and optical microscopy were carried out

- thermo-oxidative degradation of the coating was identified as cause of failure

\begin{abstract}
This paper reports the failure of an epoxy coating that was applied for corrosion prevention on the inner walls of a heat exchanger. The coating became brittle and detached from the walls of the exchanger after one year of service. An investigation was performed in order to evaluate the failure cause by means of thermal analysis, optical microscopy and infrared spectroscopy. Thermal analysis excluded an incomplete curing of the detached paint. Optical microscopy highlighted sediments, pores and cracks over the detached coating surface; infrared spectroscopy revealed vibrational bands associated with thermo-oxidative phenomena. A thermo-oxidative simulation was performed on fresh coating samples, pointing out that epoxy coating starts degrading around $100-120^{\circ} \mathrm{C}$. Taking into account the temporary malfunction of the cooling system reported by the user, the failure cause was identified in an overheating that induced a thermo-oxidative degradation of the coating and its subsequent embrittlement and detachment.
\end{abstract}

\section{Keywords}

epoxy protective coating; heat exchanger; FT-IR spectroscopy; thermo-oxidation; thermal analysis 


\section{Introduction}

Organic coatings are widely used for protection against corrosion and erosion of critical equipment's components such as heat exchangers tubing [1-3]. Among others, epoxybased paints allow for rapid, in-situ application and generally provide long-term protection $[2,3]$. This paper reports the failure of an epoxy coating that was applied for corrosion prevention on the inner walls of a heat exchanger conveying seawater. After one year of service, the plant was stopped for ordinary maintenance and the piping system was inspected. The user noticed that coating was detached from the inner walls of heat exchanger. Detached coating flakes appeared brittle and dark-colored. About four months before the failure, the user reported also a temporary interruption in the water cooling supply inside the piping. Fourier-Transform infrared spectroscopy (FT-IR) was used to detect molecular by-products typical of thermo-oxidative degradation (such as carbonyl and amide groups), while simultaneous thermal analysis (STA) to gather information about oxidative and thermal stabilities and to assess the initial decomposition temperature. As already reported [4], a crosscheck between FT-IR and STA has been successfully applied to investigate the weathering effect on coatings degradation.

\section{Experimental}

Tubing material is an Al-Brass (JIS C687T - Cu 76-79\%, Al 1.8-2.5\%, Mn $<0.2 \%, \mathrm{~Pb}$ $<0.05 \%, \mathrm{Fe}<0.05 \%, \mathrm{Ni} 0.2-1.0 \%$, Zn rem.); pipe outer diameter is $22 \mathrm{~mm}$ and wall thickness $0.5 \mathrm{~mm}$; inner pipe wall was painted with a protective epoxy coating. First coating layer (bonded to the inner pipe wall) was a red-colored epoxy paint (bisphenol-A diglycidyl ether, amine hardening agent); second coating layer (facing the conveyed fluid) was a greencolored epoxy paint (bisphenol-A diglycidyl ether, amine hardening agent). Conveyed cooling fluid inside the heat exchanger was seawater (inlet temperature $18-25^{\circ} \mathrm{C}$, outlet temperature $38-40{ }^{\circ} \mathrm{C}$ ); outer fluid water vapor (temperature: up to $130^{\circ} \mathrm{C}$ ). A schematic of the heat exchanger pipe section and the coating layers location is represented in Figure 1. Two detached coating samples (sample "A" and "B", originated from different pipe areas) were sent back for analysis. Detached samples were observed by optical microscopy (Optika SZN-2 stereo microscope) and analyzed via Fourier-Transform infrared spectroscopy (FT-IR). FT-IR spectra were acquired via a Thermo-Nicolet Nexus 470 spectrometer, equipped with a diffused reflectance accessory (DRIFT). Abrasion-Drift technique was used: an abrasive paper was used to collect samples from the coatings; a background spectrum was first collected on the abrasive paper, then a diffuse reflectance spectrum of the sample was recorded. Y-axis of FTIR spectra (\% Reflectance) have been inverted for clarity. Differential Scanning Calorimetry (DSC) measures were carried out by means of a Netzsch DSC 200 F3 Maia in calm air both on fragments detached form the pipe in order to determine the possible presence of unreacted material and / or residual solvent. The thermal cycle was set as follows: initial stand-by at $20^{\circ} \mathrm{C}$ for $10 \mathrm{~min}$; heating from $20^{\circ} \mathrm{C}$ to $200^{\circ} \mathrm{C}$ at $10 \mathrm{~K} / \mathrm{min}$. In order to understand the reasons of coating embrittlement and failure, fresh coating samples were prepared in laboratory. Specimens were obtained after mixing "green epoxy" or "red epoxy" with the amine hardening agent in a 77:23 ratio, as suggested by technical data sheet. Coatings were cured at room temperature for 24 hours, and then heated at $50^{\circ} \mathrm{C}$ for 4 hours. Thermogravimetry (TGA) and Differential Thermal Analysis (DTA) were performed on these samples in order to characterize the degradation phenomena. Materials were heated from $25^{\circ} \mathrm{C}$ to $1000^{\circ} \mathrm{C}$, with a heating rate of $10 \mathrm{~K} / \mathrm{min}$, in dynamic air, using a Netzsch STA 409 EP instrument. Fresh epoxy coatings were finally 
thermally aged in ventilated oven (temperature variation: $\pm 2^{\circ} \mathrm{C}$ ) to simulate a thermooxidative degradation. Aging tests were performed for 2 hours, at $90^{\circ} \mathrm{C}, 100^{\circ} \mathrm{C}, 120^{\circ} \mathrm{C}$, $140^{\circ} \mathrm{C}$ and $200^{\circ} \mathrm{C}$, and at $120^{\circ} \mathrm{C}$ for 16 hours. Afterwards, samples were characterized by means of FT-IR spectroscopy: a comparative evaluation among spectra of new, aged and detached samples was carried out.

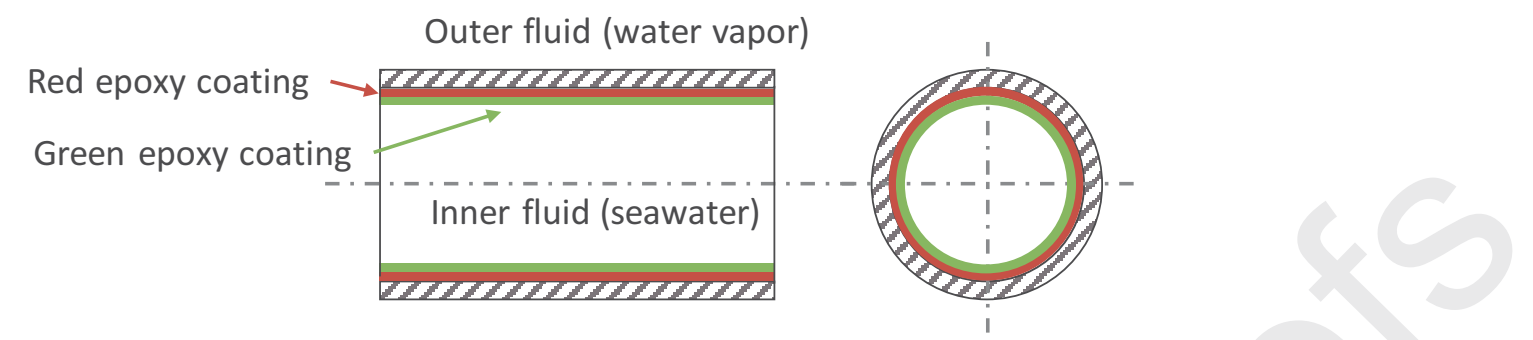

Figure 1. Schematic of heat exchanger pipe section and location of red and gren coating layers.

\section{Results}

\subsection{Visual inspection and optical microscopy}

Visual inspection of green coating on sample A shows some surface sediments and pores all over sample surface (Figure 2). At optical microscope observation (Figure 4a), many cracks can be seen; cracks are spread all over sample surface.

On red coating there are no evident porosities, but some sediments can be seen (Figure 4b), with colors ranging from ochre (lower part), to brown (central part) up to white (upper part). These deposits, probably already attached on pipe walls before coating application, were embedded inside the red coating.

Green coating on sample B (Figure 3a, Figure 5a) appears brown-tarnished and it is characterized by many surface sediments. Some small pores are noticeable, even if less abundant than in sample 1. Red coating on sample 2 (Figure 3b, Figure $5 \mathrm{~b}$ ) is characterized by large dark areas; in other areas the red coating does not show deposits or cracks.

Figure 6 shows a visual comparison of color change induced by simulated thermal aging on coatings: all samples were kept at the respective temperatures for 2 hours, except for samples at $120^{\circ} \mathrm{C}$ (which were left in the oven for 2 and 16 hours). Samples up to $120^{\circ} \mathrm{C}$ $2 \mathrm{~h}$ do not show significant color change, whereas for higher temperatures (or longer time at $120^{\circ} \mathrm{C}$ ), an overall darkening effect is noticeable.

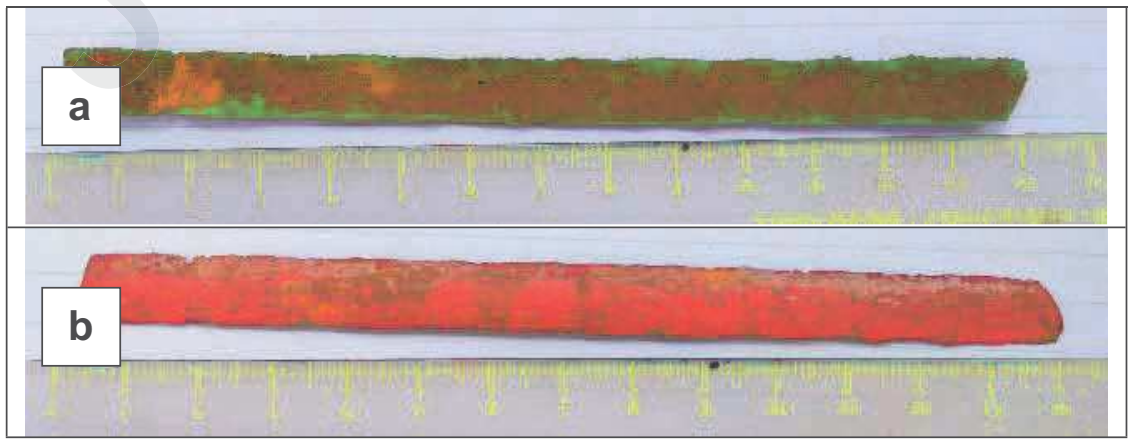

Figure 2. Visual survey of sample A: (a) inner surface of the coating, facing conveyed fluid; (b) outer surface of the coating, facing the pipe wall. 


\section{Journal Pre-proofs}

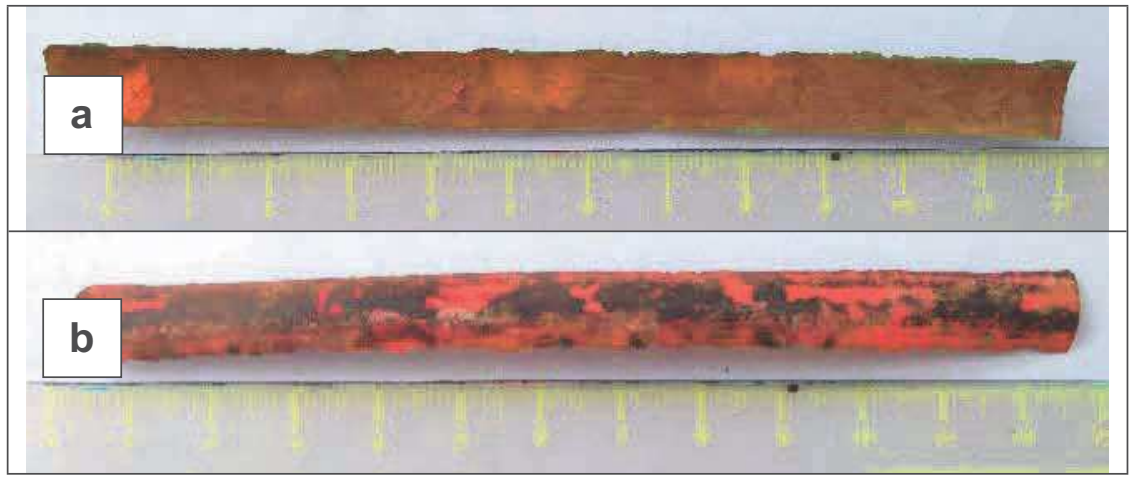

Figure 3. Visual survey of sample B: (a) inner surface of the coating, facing conveyed fluid; (b) outer surface of the coating, facing the pipe wall.
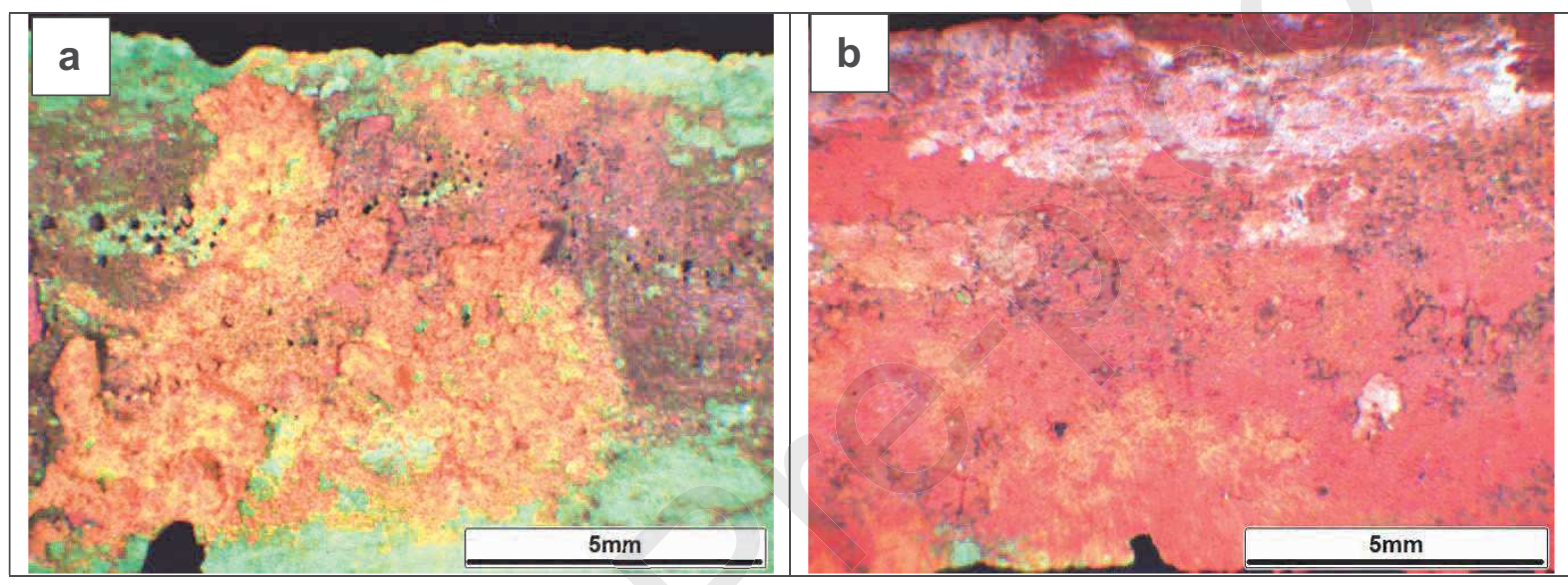

Figure 4. Optical microscopy of sample A: (a) inner surface of the coating, facing conveyed fluid; (b) outer surface of the coating, facing the pipe wall (right).
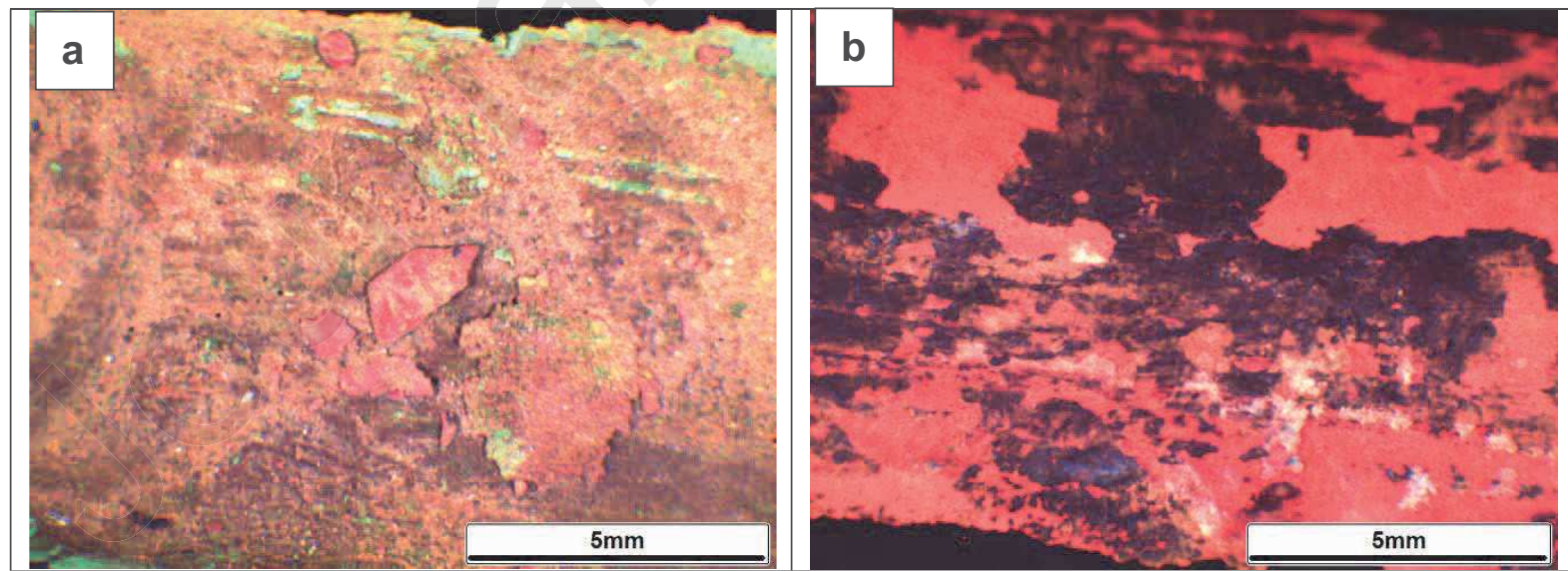

Figure 5 - optical microscopy of sample B: (a) inner surface of the coating, facing conveyed fluid; (b) outer surface of the coating, facing the pipe wall. 


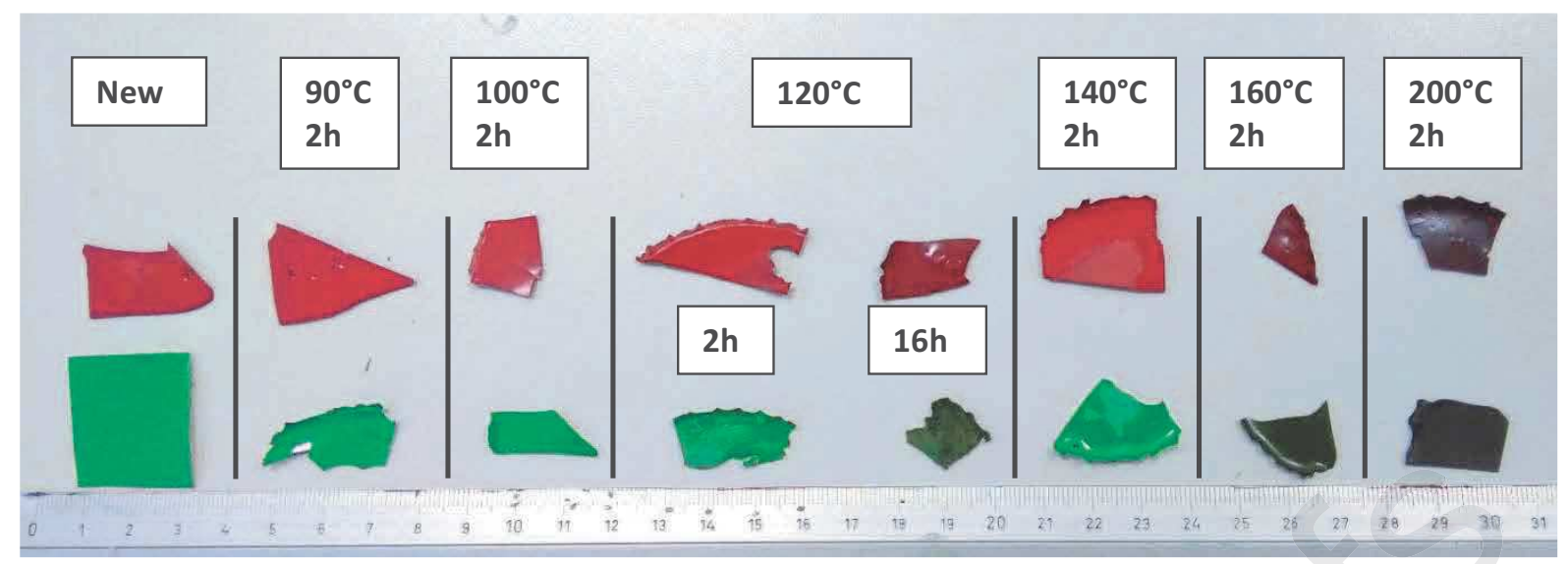

Figure 6 - Color change in samples subjected to thermal treatments.

\subsection{FT-IR spectroscopy}

FT-IR spectra of detached coating were compared with spectra of new samples realized in laboratory. From FT-IR data analysis, new coatings show vibrational bands compatible with an epoxy resin derived from mixed aliphatic-aromatic chains and an amine hardener [5-7]. Identified vibrational bands are summarized in Table 1.

Table 1. FT-IR bands of coating obtained in laboratory and coating detached from pipe walls.

\begin{tabular}{|c|c|c|}
\hline \multicolumn{2}{|c|}{ Band $\left(\mathrm{cm}^{-1}\right)$} & \multirow{2}{*}{ Assignment } \\
\hline New coating & Detached coating & \\
\hline$\sim 3420$ & -3420 & $\mathrm{OH}$ stretch \\
\hline 3050 & 3050 & arom $\mathrm{CH}$ stretch \\
\hline 2960 & 2960 & $\mathrm{CH}$ stretch \\
\hline 2925 & 2925 & $\mathrm{CH}_{2}$ stretch (asym.) \\
\hline 2870 & 2870 & $\mathrm{CH}_{2}$ stretch (sym.) \\
\hline- & 1730 & $\mathrm{C}=\mathrm{O}$ stretch \\
\hline & 1650 & Amide - I \\
\hline 1605 & 1605 & \\
\hline 1580 & 1580 & arom $\mathrm{C}=\mathrm{C}$ stretch \\
\hline 1512 & 1512 & aroml. C-c stretch \\
\hline 1470 & 1470 & \\
\hline 1440 & 1440 & $\mathrm{CH}_{2}$ bending deformation \\
\hline 1292 & 1292 & C-O-C stretch \\
\hline 1250 & 1250 & C-N stretch \\
\hline 1271 & 1271 & $\mathrm{C}=\mathrm{O}$ deformation \\
\hline 1185 & 1185 & C-O stretch \\
\hline 1040 & 1040 & $\mathrm{C}-\mathrm{O}-\mathrm{C}$ stretch \\
\hline
\end{tabular}

From the comparison (Figure 7) between the spectra of fresh green coating and detached green sample two additional peaks (at $1730 \mathrm{~cm}^{-1}$ and $1650 \mathrm{~cm}^{-1}$ ) can be noticed in the latter one. The first peak, related to carbonyl stretch, is usually associated with generic thermo- 
oxidative degradation of polymers, while the second band is related to an "amide-l" vibration (carbonyl and C-N vibration overlap), typically linked to amine group oxidation [7-9]. Fresh red coating shows the same vibrational bands already seen for green paint; the only difference consists in a small peak linked to carbonyl group, most likely due to the presence of a filler or a dye. Spectra comparison (Figure 7) between new and detached red samples shows an extra peak at $1650 \mathrm{~cm}^{-1}$ (amide-I) and an increase in intensity of $1730 \mathrm{~cm}^{-1}$ peak (carbonyl stretch). These peaks, already examined in the previous case (green coating), are linked to thermo-oxidative degradation phenomena of epoxy resins [8-10].

Aged coating spectra, if compared to new coating ones (Figure 8 and Figure 9), show the already mentioned extra peaks $\left(1730 \mathrm{~cm}^{-1}\right.$ and $\left.1650 \mathrm{~cm}^{-1}\right)$. These peaks start emerging around $100-120^{\circ} \mathrm{C}$. Intensities of degradation-related peaks rise with the aging temperature. The same peaks are visible in the spectrum acquired from coating detached from pipe walls, although the relative intensity ratio is different. The comparison between spectra of coatings aged for 2 hours at $120^{\circ} \mathrm{C}$ with those belonging to coatings aged for 16 hours at the same temperature (Figure 9, Figure 10 and Figure 11) shows how the degradation-related peaks $\left(1730 \mathrm{~cm}^{-1}\right.$ and $\left.1650 \mathrm{~cm}^{-1}\right)$ intensities increase for longer aging times.

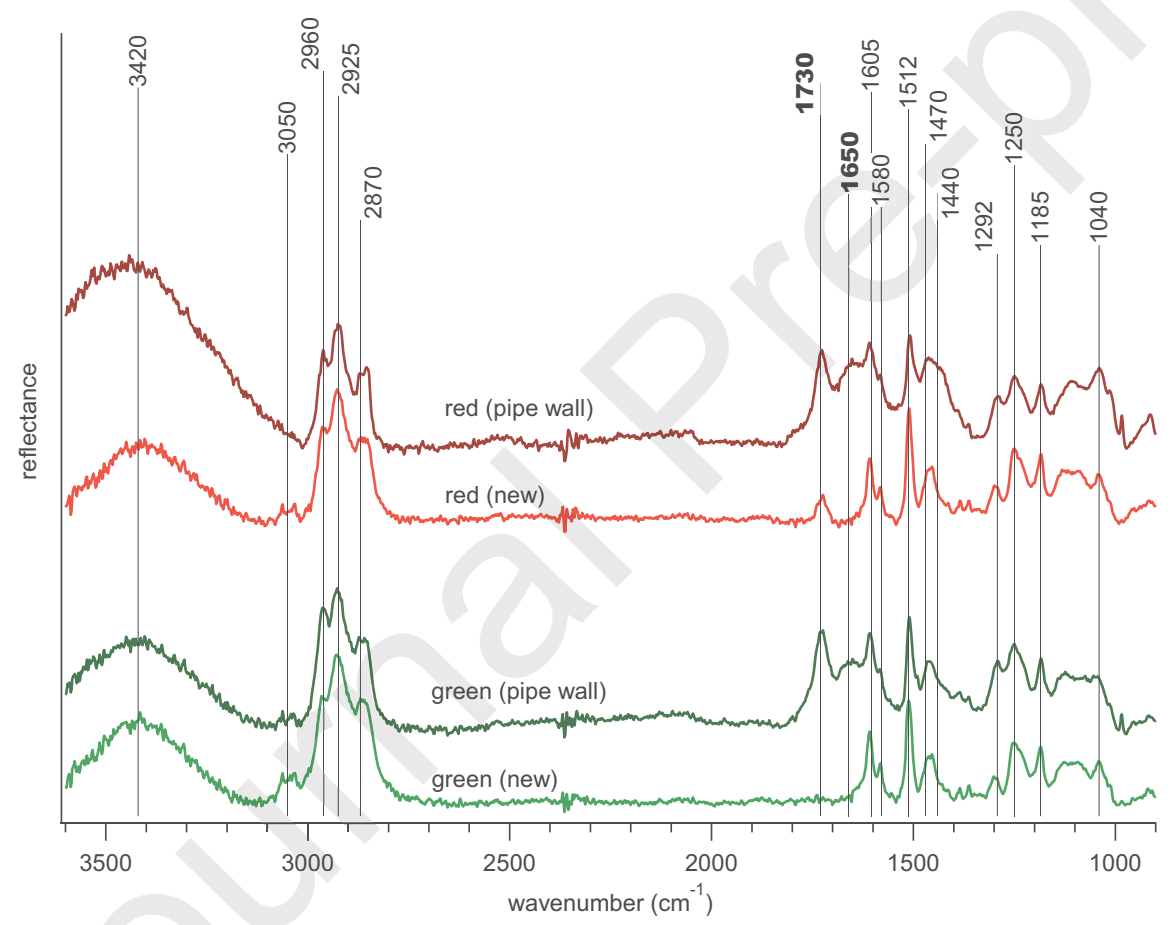

Figure 7. FT-IR spectra of new coatings and coatings detached from the pipe wall, from bottom to top: fresh green paint, detached green sample, fresh red paint and detached red sample. 


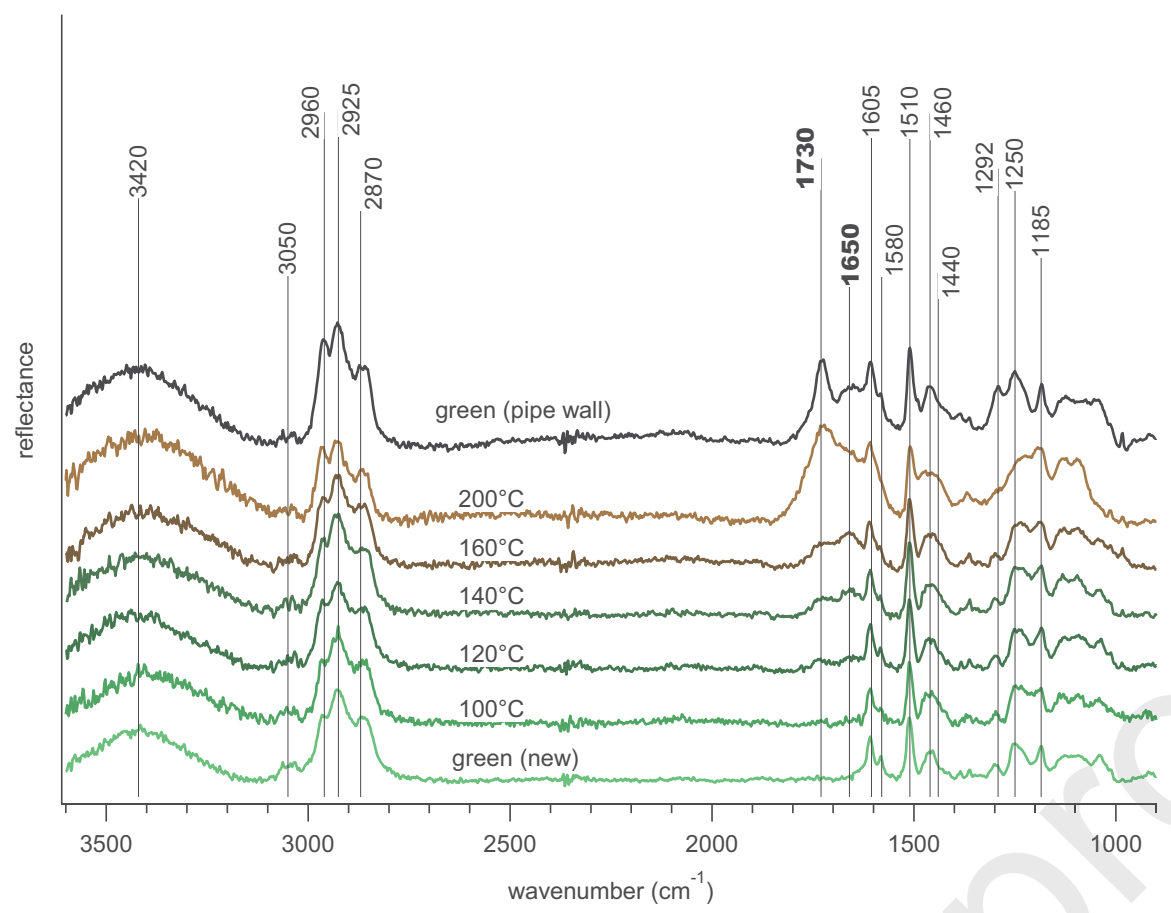

Figure 8. FT-IR spectra comparison of laboratory aged green sample with fresh green coating and detached green coating, from bottom to top: new green coating, aged green coatings (aging temperature above the curves) and green coating detached from the pipe wall.

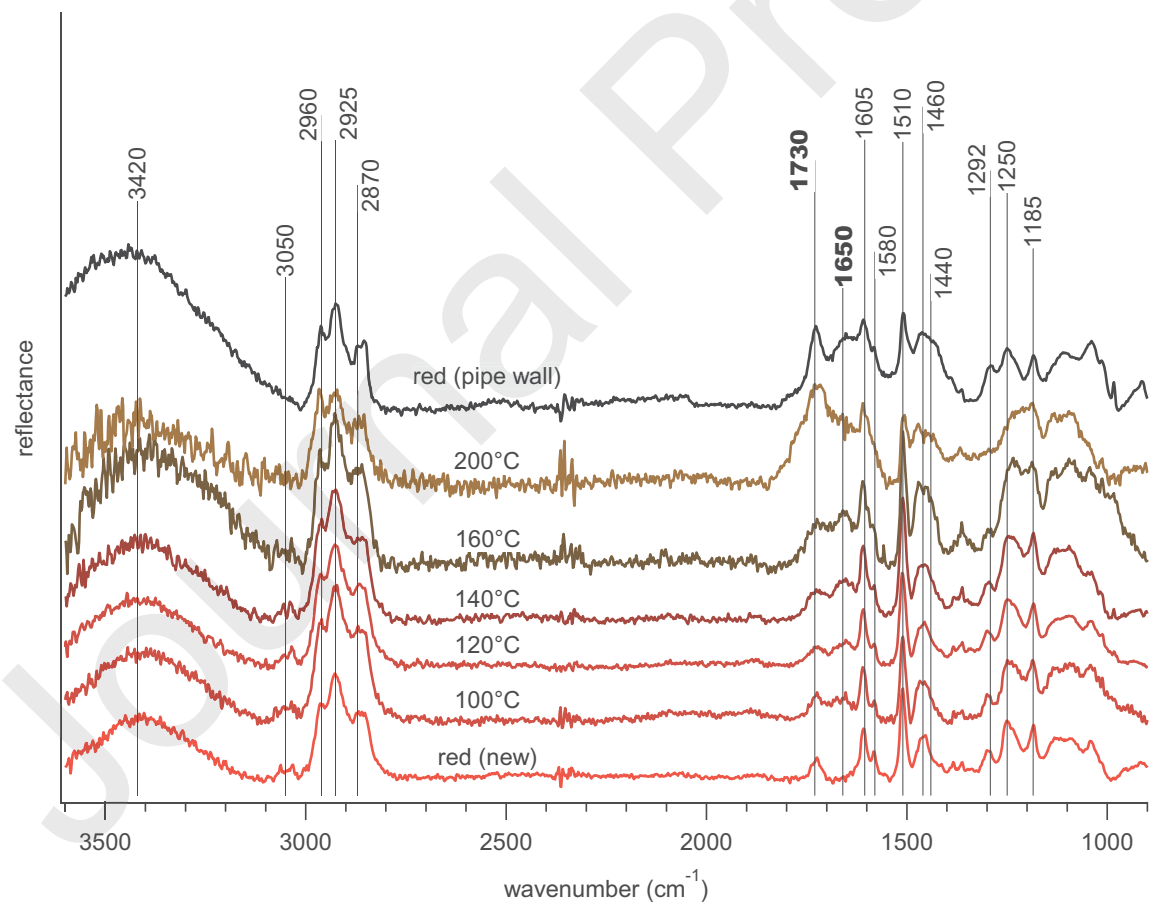

Figure 9. FT-IR spectra of aged red coating compared with new and detached red coatings, from the bottom: new red coating, aged red coatings (aging temperature above the curve) and red coating detached from the pipe wall. 


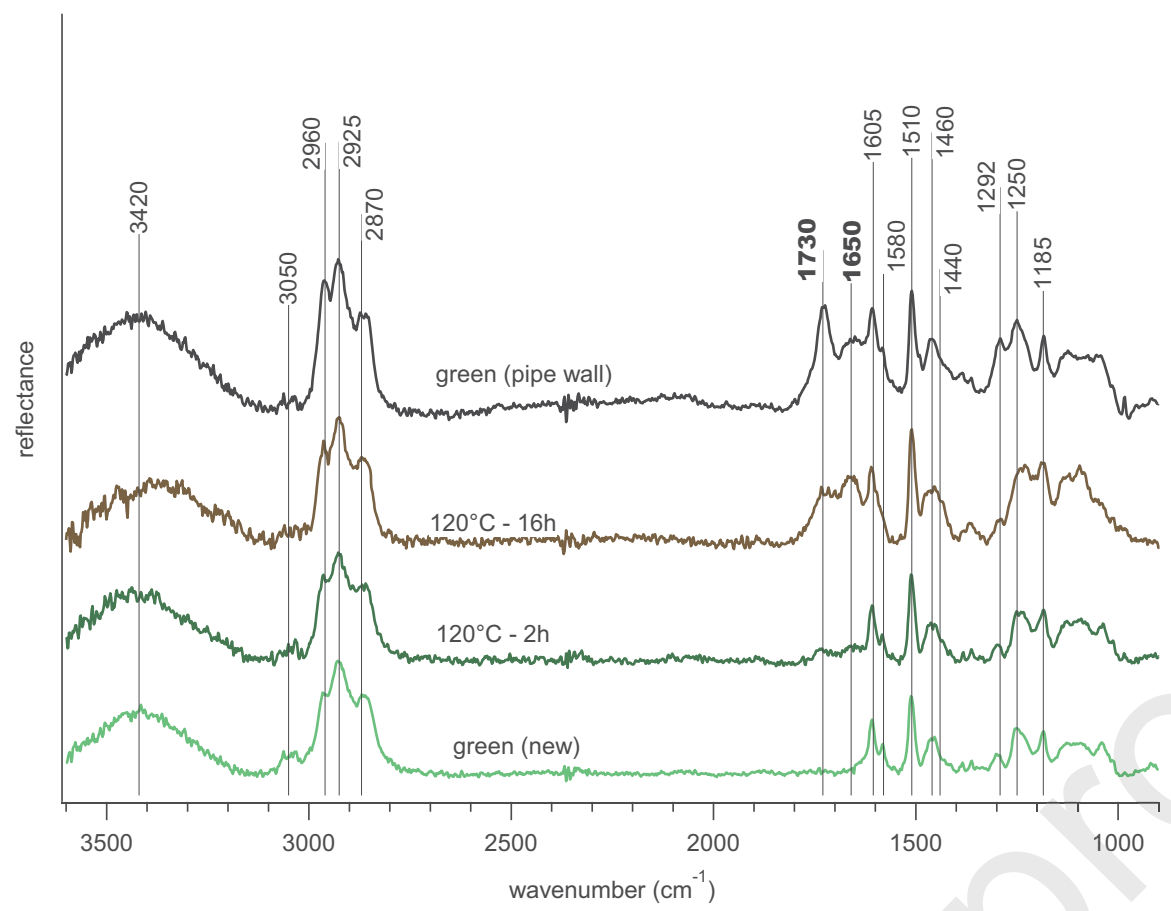

Figure 10. FT-IR spectra of aged green coatings at $120^{\circ} \mathrm{C} 2 \mathrm{~h}$ (dark green curve) and $16 \mathrm{~h}$ (brown curve), new green coating (bottom green curve) and green coating detached from the pipe wall (black curve).

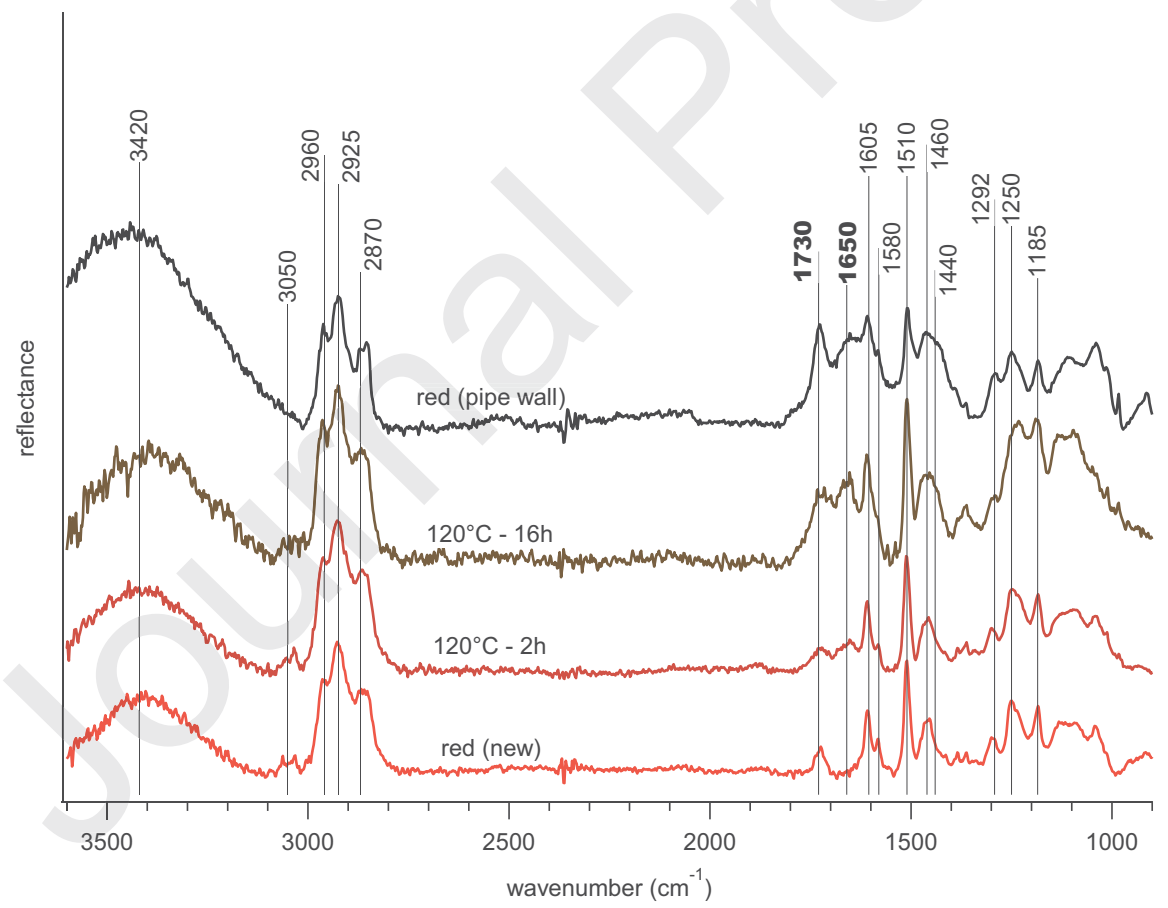

Figure 11. FT-IR spectra of new red coating (bottom curve), red coatings aged at $120^{\circ} \mathrm{C}$ for $2 \mathrm{~h}$ (dark red curve) and for $16 \mathrm{~h}$ (brown curve) and red coating detached from the pipe wall (black curve). 


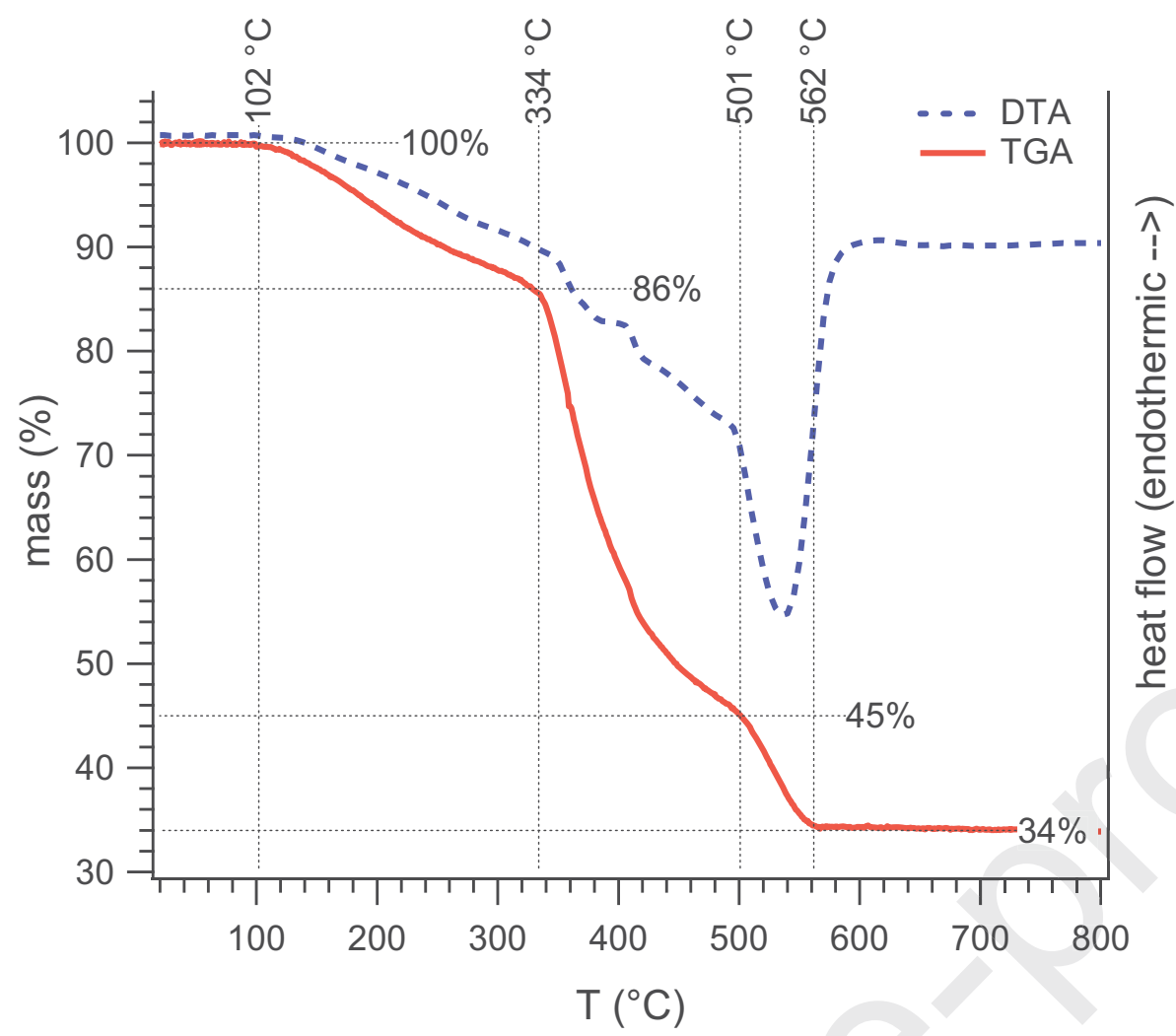

Figure 12. TGA and DTA curves of coating produced in laboratory.

\subsection{DSC-TGA measurements}

DSC measurements on the coating detached from the pipe wall and on fresh prepared coating did not show any exothermic peaks in the $20^{\circ} \mathrm{C}-200^{\circ} \mathrm{C}$ range, pointing out a complete cross-linking $[11,12]$. The fresh coating showed a glass transition temperature around $165^{\circ} \mathrm{C}$, in line with previously reported data for similar compounds [13]. We performed simultaneous thermal analysis (TGA and DTA curves) on the fresh coating, to study mass change and heat evolution as a function of temperature. TGA and DTA are reported in Figure 12. Coating starts losing mass above $100^{\circ} \mathrm{C}$; a first degradation step $\left(102-334^{\circ} \mathrm{C}\right)$ correspond to a loss of $14 \%$ original sample mass; a second, faster degradation step $\left(335-501^{\circ} \mathrm{C}\right)$ - residual mass $45 \%$; and the final step concluding around $560^{\circ} \mathrm{C}$. Residual inorganic mass is about $33 \%$ of the original sample mass. The starting temperature of the first degradation step $\left(102^{\circ} \mathrm{C}\right)$ complies with the starting of the thermooxidative degradation detected after aging simulation in oven. DTA show evolution of heat between $110^{\circ} \mathrm{C}$ and $600^{\circ} \mathrm{C}$, with two exothermic feature between $102-300^{\circ} \mathrm{C}, 330-500^{\circ} \mathrm{C}$, and one exothermic peaks around $540^{\circ} \mathrm{C}$, corresponding to the mass decreasing steps seen in TGA.

\section{Conclusions}

An investigation has been performed in order to evaluate the degradation of some coating flakes, detached from the inner wall of a heat exchanger, by means of optical microscopy, 
infrared spectroscopy (FT-IR) and thermal analysis (DSC, STA). The following conclusions derive from these analyses:

- $\quad$ optical microscopy shows some surface sediments, pores and many cracks spread all over sample surface;

- $\quad$ FT-IR spectroscopy reveals two peaks at $1730 \mathrm{~cm}^{-1}$ and $1650 \mathrm{~cm}^{-1}$ for detached coating samples: the former is related to carbonyl stretch and usually associated with generic thermo-oxidative degradation of polymers, while the latter is related to an "amide-l" vibration;

- $\quad$ the absence of exothermic peaks in DSC traces points out that paints were completely cured;

- $\quad$ FT-IR spectroscopy performed after thermal aging tests demonstrates how the degradation of both red and green resins can be simulated using an oven. Thermooxidation starts at $100-120^{\circ} \mathrm{C}$, and increases both for temperature and exposure time;

- $\quad$ TGA shows that epoxy coating starts losing weight above $100^{\circ} \mathrm{C}$.

Considering the temporary stop/malfunction in the water cooling supply reported by enduser, experimental findings leads to the conclusion that coatings were exposed to vapor $\left(120-130^{\circ} \mathrm{C}\right)$ for several hours, without the cooling effect of the conveyed fluid. This situation has most likely led to pipe wall overheating (over $100-120^{\circ} \mathrm{C}$ ), causing a thermo-oxidative degradation of the coating. This degradation led to an embrittlement and change in the coating surface chemistry, negatively affecting its adhesion properties [14] and causing a subsequent detachment from the pipe, with the thermal stress resulting from the overheating being a concurrent cause. In normal operative condition, conveyed seawater has been able to avoid this overheating problem. 


\section{References}

[1] M. Poelman, M.-G. Olivier, N. Gayarre, J.-P. Petitjean, Electrochemical study of different ageing tests for the evaluation of a cataphoretic epoxy primer on aluminium, Prog. Org. Coat. 54 (2005) $55-62$.

[2] L. Fedrizzi, F. Andreatta, L. Paussa, F. Deflorian, S. Maschio, Heat exchangers corrosion protection by using organic coatings, Prog. Org. Coat. 63 (2008) 299-306.

[3] H.R. Reuter, M. Owen, J.L. Goodenough, The Antifouling Effects of Copper-Oxide Filler Incorporated Into Paint-Based Protective Films Applied to Steam Surface Condenser Tubes, J. Therm. Sci. Eng. Appl. 10 (2018) 041015.

[4] L. Marsich, A. Ferluga, L. Cozzarini, M. Caniato, O. Sbaizero, C. Schmid, The effect of artificial weathering on PP coextruded tape and laminate, Compos. Part Appl. Sci. Manuf. 95 (2017) 370376. doi:10.1016/j.compositesa.2017.01.016.

[5] R.E. Smith, F.N. Larsen, C.L. Long, Epoxy resin cure. II. FTIR analysis, J. Appl. Polym. Sci. 29 (1984) 3713-3726.

[6] G. Socrates, Infrared and Raman characteristic group frequencies: tables and charts, John Wiley \& Sons, 2004.

[7] C. Damian, E. Espuche, M. Escoubes, Influence of three ageing types (thermal oxidation, radiochemical and hydrolytic ageing) on the structure and gas transport properties of epoxyamine networks, Polym. Degrad. Stab. 72 (2001) 447-458.

[8] E. Ernault, E. Richaud, B. Fayolle, Thermal oxidation of epoxies: Influence of diamine hardener, Polym. Degrad. Stab. 134 (2016) 76-86.

[9] Y. Zahra, F. Djouani, B. Fayolle, M. Kuntz, J. Verdu, Thermo-oxidative aging of epoxy coating systems, Prog. Org. Coat. 77 (2014) 380-387.

[10] F. Delor-Jestin, D. Drouin, P.-Y. Cheval, J. Lacoste, Thermal and photochemical ageing of epoxy resin-Influence of curing agents, Polym. Degrad. Stab. 91 (2006) 1247-1255.

[11] L. Gherlone, T. Rossini, V. Stula, Powder coatings and differential scanning calorimetry: the perfect fit, Prog. Org. Coat. 34 (1998) 57-63.

[12] A. Husain, S. Al-Bahar, J. Chakkamalayath, A. Vikraman, A. Al Ghamdi, T. Kamshad, R.S. Siriki, Differential scanning calorimetry and optical photo microscopy examination for the analysis of failure of fusion bonded powder epoxy internal coating, Eng. Fail. Anal. 56 (2015) 375-383.

[13] E. Ernault, E. Richaud, B. Fayolle, Thermal oxidation of epoxy/amine followed by glass transition temperature change, Polym. Degrad. Stab. 138 (2017) 82-90.

[14] M. C. Celina, A. R. Dayile, A. Quintana, A perspective on the inherent oxidation sensitivity of epoxy materials, Polymer, 54 (2013) 3290-3296

Funding sources: this research did not receive any specific grant from funding agencies in the public, commercial or not-for-profit sectors. 